\title{
Die Bedentung der Zwillingsforschung für die Hals-, Nasen- und Ohrenheilkunde
}

\author{
Von M. Schwarz, Tübingen
}

An einem Material von 60 eineiigen und 36 zweieiigen Zwillingen läßt sich sowohl an den Formverhältnissen der Nasenscheidewand, als auch in der Struktur des Warzenfortsatzes (Pneumatisation) bei den eineiigen Partnern ein recht häufiges Übereinstimmen beobachten. Ein eineiiges Paar mit atropischer Rhinitis zeigt gleiche und mit der Mutter übereinstimmende Verhältnisse. Bei einem weiteren eineiigen Paar stimmt das Krankheitsbild der Nasennebenhöhlen, eine diffuse Polyposis, sowie die sekundären Veränderungen im Naseninnern genau überein. Auch die Befunde am lymphatischen Schlundring sind bei eineiigen Paaren auffallend gleich. Besonders bemerkenswert sind auch die Trommelfellbilder bei den Eineiigen. Auch hier findet sich eine große Übereinstimmung nicht nur hinsichtlich Form, Farbe und Lage, sondern auch hinsichtlich pathologischer Veränderungen. Die Verdickungen, Atrophien, Narbenbildungen, Verkalkungen und persistierenden Perforationen der Membranen stimmen nicht nur im Grad überein, sondern liegen nicht selten sogar an gleicher Stelle. In den Zwillingsfällen von akuter bezw. chronischer Erkrankung des Mittelohres ist der Hörbefund übereinstimmend, ebenso bei einer professionellen Schwerhörigkeit. Ein eineiiges Paar mit dem Krankheitsbild der Otosklerose zeigt genau dasselbe Hörbild.

Aus diesen Befunden ergeben sich weitgehende Aufschlüsse über die anlagemäßig bedingte Entwicklung mancher anatomischer und pathologischer Varietäten. Weiterhin läßt sich für den Kliniker der wichtige Schluß ziehen, daß für das Zustandekommen einer Infektion und ihrer Abwehr durch die Schleimhaut in hohem Maße hereditäre Faktoren von Bedeutung sind.

\section{Erbpsychologische Untersuchungen an Zwillingen}

\author{
Von 0. v. Verschuer, Berlin-Dahlem
}

(Mit 3 Textfiguren)

Die Ergebnisse der Familienuntersuchungen zum Problem der Vererbung normaler psychischer Eigenschaften sind wenig befriedigend. Peters, dem wir die umfassendste Bearbeitung dieses Themas verdanken, kommt za dem resignierten Schluß, daß eine Vererbung psychischer Eigenschaften sich „nicht. streng beweisen, sondern nur wahrscheinlich machen läßt". Und weiterhin lesen wir in einer späteren Arbeit von demselben Autor: "Die vorliegenden psychologischen Erblichkeitsuntersuchungen haben sich ..... 